\title{
The SIMPLE methodology for supporting innovations in the field of renewable energy and energy efficiency
}

\author{
Olof Hjelm* \\ Environmental Technology and Management, Department of Management and Engineering, Linköping \\ University, 58183 Linköping, Sweden \\ *Corresponding author. Tel: +46 13285647, Fax: +46 13281100, E-mail: olof.hjelm@liu.se
}

\begin{abstract}
In this article, I present my experiences stimulating development of new products and services in small companies in the environmental arena. The focus on small companies is justified since many new innovations originate from such companies and they often have special needs compared to larger companies. In the region of Östergötland Sweden, we have developed a model called SIMPLE (Successful implementation of eco-design in small enterprises) to support small companies' environmental innovations. SIMPLE uses the Triple Helix approach. Triple Helix is often used to describe the interaction between university, government, and industry to promote innovation by building on active participation and interaction between regional actors. In short, the SIMPLE methodology uses coaching, network activities and education, and financial support to encourage development of new ideas. Three cases are presented to illustrate the diversity of innovations that can be supported using the SIMPLE methodology. Observations suggest that individual company's needs must be the main concern of any methodology and networks can significantly stimulate individuals and organizations to speed up the development process and time to market.
\end{abstract}

Keywords: Innovation, Small Companies, Renewable energy, Energy efficiency.

\section{Introduction}

A rapidly growing demand for renewable energy solutions and energy efficient products calls for innovations. New products and services are realized in a large diversity of organizations including companies of various size and character. This paper focuses on the small company. Product and service development is strategically important for the development of a company, yet Gibb and Scott [1] noted the absence of formal planning models in small companies. Even when the development is strategically important, much of the planning is iterative and not formalized. This is rather far from the linear and structured product and business development models often presented in student textbooks (see Ulrich and Eppinger [2]). Gibb and Scott [1] also noted the importance of strategic awareness and personal commitment. One of the recommendations the authors give to policy makers is to encourage "the development of the strategic awareness and personal commitment of the owner manager”.

To stimulate environmentally driven development of small companies, several national and regional initiatives are currently on going in Sweden and Europe. Different approaches and methods can be used and the aim of this paper is to present a methodology, the SIMPLE methodology, developed in the region of Östergötland, SE Sweden. The paper starts with a general description of the methodology followed by three cases of small companies developing new products and services. Special focus is on innovations in the field of renewable energy and energy efficiency. The experiences using the methodology are discussed and conclusions are drawn on the general applicability of the presented methodology.

\section{Methodology}

The approach used in this study can be referred to as action research. The description of the SIMPLE methodology and all findings in this paper primarily are based on my observations, 
as a researcher, actively taking part in the general management of the project. The SIMPLE methodology has been developed and tested in three different business development projects involving approximately 50 SMEs in Östergötland, Sweden between 2002 and 2010. The findings presented in this article are from the latest project lasting from May 2008 to December 2010. Earlier descriptions of the methodology can be found in Hjelm [3] and Rennie et al. [4]. My tasks in the current project were to arrange network meetings and to coach actively the companies. However, I did not take part in the individual development projects at the companies. At the end of the project (September-October 2010), I performed semi-structured interviews with company representatives. During these interviews, the respondents were asked to describe their product development and their experiences with the project. I also had continual contact with the companies during the project and collected documentation such as consultancy reports and marketing material produced by the companies. All companies made project plans for the development projects and wrote a short report after finalizing their projects.

In total, 26 companies took part in the latest project including furniture producers, creativity consultants, and heat pump producers. For this paper, I have made a selection of three companies based on the character of their business activities and development. All three are active in the field of renewable energy and energy efficiency, but I tried to select companies having differing characteristics to demonstrate the diversity of companies/innovations that can be supported using the SIMPLE methodology. General facts about the case study companies are found in Table 1.

Table 1. General facts regarding case study companies.

\begin{tabular}{cccc} 
Company & $\begin{array}{c}\text { Size } \\
\text { (employees) }\end{array}$ & Main competence area & Development project \\
$\begin{array}{c}\text { Rydell \& Lembke, } \\
\text { Kyl och Värmeteknik } \\
\text { AB }\end{array}$ & 11 & $\begin{array}{c}\text { Construction and } \\
\text { production of cooling and } \\
\text { heating equipment }\end{array}$ & $\begin{array}{c}\text { New generation of cooling } \\
\text { and heat pump }\end{array}$ \\
\hline Pencraft Services AB & 3 & $\begin{array}{c}\text { Renewable energy } \\
\text { solutions for generation } \\
\text { of electricity and hot } \\
\text { water }\end{array}$ & $\begin{array}{c}\text { Energy efficient heater } \\
\text { (biogas driven) }\end{array}$ \\
\hline Biototal AB & 8 & $\begin{array}{c}\text { Waste product } \\
\text { management. Nutrient } \\
\text { recycling }\end{array}$ & $\begin{array}{c}\text { Harvesting of biomass for } \\
\text { removal of nutrients and } \\
\text { substrate for biogas } \\
\text { production }\end{array}$ \\
\hline
\end{tabular}




\section{Description of the SIMPLE methodology}

The SIMPLE-model builds on formal and informal networks between companies, the project team, and external resources. This can be visualized as a triangle as described in Figure 1.

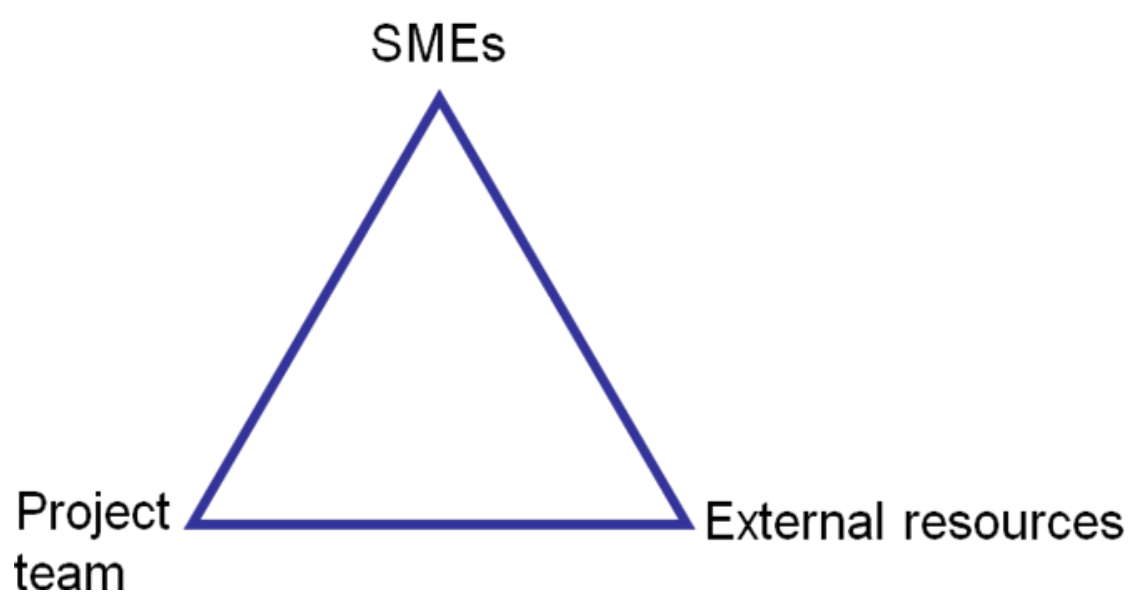

Fig 1. The SIMPLE Model. Each corner represents a different type of network that together constitute the project members. Interactions between the different networks are further described in the text. SMEs $=$ Small and Medium Sized Enterprises.

To explain the different components and structure of the model, it is beneficial to know the underlying goals for the different development projects using the methodology. The main aim has been to create economic growth by stimulating product and business development in small companies and simultaneously solving environmental problems. A secondary aim has been capacity building among regional actors for regional sustainable development and building up a strong network of companies, authorities, and business support organizations in this field. The model is inspired by the Triple Helix approach. Triple Helix is a model used to describe the interaction between university, government, and industry to promote innovation in a region. The triple spiral symbolises the dynamic cooperation between the three actors and the model builds on active participation and interaction between regional actors. A common vision is developed and resources for development are coordinated to increase the capacity for innovations and produce a higher yield as related to the resources spent.

\subsection{Small and medium sized enterprises (SMEs)}

Two types of companies have participated in the projects. One group includes companies which have products that aim to reduce environmental problems (sometimes labelled as Cleantech companies), while the other group involves companies developing ordinary products that take into consideration environmental concerns (environmentally conscious design). The companies included had been established for at least a couple of years (no start ups were allowed) and had the financial and personal resources to start and finalize a development project. Company size varied between 2 and 75 employees.

Three types of development projects were conducted. The first type included projects that aimed to reduce use of material and energy, to increase conscious choices of material, to substitute toxic materials or chemicals, and to improve recyclability, etc. The second ype of development projects included products or services that solve an environmental problem. The 
third type included products or services that provide the same customer value but with significantly lower environmental impact compared to established products or services.

\subsection{Project team}

From the beginning, the project team was designed to comprise individuals and organizations with complementary skills. During all three projects, the organizations represented in the project team have been the County Administrative Board of Östergötland, Linköping University, and the business support organization ALMI företagspartner AB. All actors were members of a larger regional partnership for stimulating regional development and had agreed on a set of regional development strategies that included stimulation of environmentally driven business.

The County Administrative Board is the national government representative office in the county of Östergötland. The Administrative Board has many responsibilities and those of special relevance for this study are development of business and trade as well as protection of the environment. Although these activities are normally managed by different offices, both offices were included in the project reported in this article. The County Administrative Board had the role as project owner and provided administration duties and co-financing.

ALMI företagspartner $\mathrm{AB}$ is a state-owned company that provides financing and business development. Each region has a local ALMI-company working together with other actors to improve regional development. It has daily contacts with companies and helps support innovation, a focus of particular interest in this article. As a consequence, ALMI has a very broad network of consultants and other business developers. Before the start of environmental development projects, they had little experience with environmental considerations in business development. Therefore, one ambition has been to develop skills and experience among ALMI-officers in this type of business support.

The local university, Linköping University, added the knowledge of environmental technology and management skills to the project team. The university joined the project to become more involved in direct business development and interact more with the society, acting as a bridge between the academy and business. Zilahy et al. [5] discussed the role of academia in fostering sustainable regional development and give several examples of roles universities can take as first movers and as a resource that offers competent staff and knowledge of the complex issue of sustainable development, goals all in line with the role Linköping University has had in these projects. Furthermore, the university acted as a change agent [6] together with the other organizations in the project team trying to accelerate the region's transition towards sustainability.

\subsection{External resources}

The external resources are a very loose and informal network of consultants, researchers, students, industrial designers, research institutes, etc. who were found to have the skills needed for in the development projects. This group was not determined beforehand; however, depending on the needs of each individual company in the project, these resource organizations were identified by the project team or the individual company. This is further described below.

\subsection{Way of working}

The different steps in the model are presented and explained below. 


\subsubsection{Start up}

After deciding to start a new project (often after securing financing), one of the first tasks for the project team was to find companies willing to enter the project so as to develop the network. The process of finding companies was started by compiling a long list of potential companies. This list was shortened (about 20-30 companies) by scrutinizing each company's line of business, financial status, etc. Companies also were identified if they already had approached one of the project team organizations seeking cooperation. In selecting companies, no special line of business was favoured; instead we sought diversity. A first individual visit was done to present the project and learn more about the company's activities and its ambitions and ideas for development. If the company was judged as suitable, it was offered a place in the project. Finally, an agreement was signed between the company and the project. After a suitable number of companies (7-10) had joined the project, the network was closed and all companies met for a first network meeting.

\subsubsection{Network meetings}

Network meetings can have many purposes. In the SIMPLE model, we used four to six meetings for education, exchange of experiences, and stimulation of individual meetings between the companies. Experts from academia and business were invited to present lectures and workshops on subjects decided by the group members jointly. These forums included information about eco-design methodologies, intellectual property rights, marketing, and sales. Each network meeting also had a designated time for the companies to present their recent development activities and experiences gained during the process. These sharing of experiences induced further discussion and also inspired the other companies in their development projects.

\subsubsection{Individual development project}

As indicated above, all companies worked on an individual development project. Typically, this involved development of a new customer's offer. The aim and activities of the development project were described in a simple project plan, and based on this plan a decision was made for financial support. This support (a consultancy check) could be used to cover $50 \%$ of the costs incurred by the company for hiring of external resource organizations. The companies did not participate in the exact same activities, so each company decided what activities to support using this financial aid. Typical activities were pre-studies, design, prototype construction, testing, and verification.

\subsubsection{Coaching activities}

Members of the project team had regular contact with each company via telephone and faceto-face meetings. At these contacts, the development projects were discussed, and eventual changes or extra need of support (such as longer discussions with the project team or meetings with other experts) were discussed.

\subsubsection{Completion}

Each group worked for approximately 18 months. When completing a group, the results in new products and services and knowledge gained were collected via interviews and written reports. To strengthen the benefits of reporting, a publication for each project was produced and a public exhibition and seminar was arranged to market the participating companies and their projects. These seminars also intended to stimulate further development both in the participating companies and among other actors attending these events. 


\section{Cases}

To illustrate the diversity of development projects that can be supported, the following section contains a description of three small companies that participated in the project. For each company, a short general presentation is given followed by their development project.

\subsection{Rydell \& Lembke Kyl och Värmeteknik AB}

This company (11 employees) builds cooling and heating equipment. Within the project, they developed a new generation of a combined refrigeration machine and heat pump, a combination that has many applications. The method is based on refrigerants encapsulated in small, sealed systems and is built on a different technical platform compared to conventional cooling machines.

\subsection{Pencraft Services $A B$}

Pencraft Services (three employees) mainly works with new product development. Its main business area is renewable energy solutions for generation of electricity and hot water. In the current development project, they have been developing energy efficient heating solutions for tap hot water and heating in family houses or small apartment buildings. The system is built on an accumulator for heat storage combined with an air/water heat pump, solar panels, and an extra facility for peak heat demands. All parts of the system are built on existing technologies except the extra device for peak heat demands. The company wanted to solve the peak heat demand by using a burner driven by biofuels. In the project, several options were evaluated and finally biogas was chosen as the fuel for the burner. Consequently, the company developed such a burner to complete the energy system for hot tap water and heating.

\subsection{Biototal $A B$}

Biototal (eight employees) is active in nutrient recycling and their general business idea is to recycle nutrients from different wastes. Recycling is achieved by quality assurance of wastes, nutrient balance calculations, and mediation of different nutrient-rich waste products. For example, mediation of by-products from biogas production can produce fertilizer in agriculture. The development project run in this project was a feasibility study for harvesting of biomass from highly eutrophicated waters. This harvested biomass could then be used as a substrate for biogas production and the by-products formed could be used as fertilizer in agriculture. By creating this eco-cycle, several environmental benefits are achieved including substitution of fossil fuels via biogas production and replacement of energy demanding production of commercial fertilizers, removal of nutrients from the water environments, replacement of non-renewable fertilizer with bio-fertilizers in agriculture, and finally increased biodiversity in water environments as a result of the harvesting. The feasibility study highlighted several opportunities and Biototal is currently conducting the first largescale field tests to verify the results of the feasibility study.

\section{Discussion and conclusions}

Two of the cases presented above resulted in new products introduced on the market (Rydell \& Lembke and Pencraft Services). Biototal is still performing field experiments needed before going to market. This subsample illustrated fairly well the general results of the project. Out of 26 companies, only three did not develop any new products or services. The reasons for this were market problems or that pre-studies identified already existing technologies available. At the end of the project, company leaders from the participating 
companies were asked about their experiences of being part of the project. The experiences were generally positive. More specifically, they mentioned three major benefits of being part of the project: creation of networks, development of contacts with the university and other support organizations, and receiving extra funding for financing the development projects.

As mentioned in the introduction, Gibb and Scott [1] noted the absence of formal planning models in small companies; hence they recommended that policy makers encourage strategic awareness and personal commitment. In the SIMPLE model, we have addresses Gibb and Scott's concerns in several intertwined ways: networking, education, financial support, and direct coaching. The SIMPLE-methodology is based on the assumption that networks can significantly stimulate business development. It can be argued that small companies always work in networks since they cannot do everything themselves because of their small size [7]. There are many different forms of networks. In this model, we use strategic formalized networks as well as informal networks. Strategic networks can be defined as a cooperative relationship between two or more companies that i) have made an active choice to cooperate and ii) provide some sort of representative for the strategic network [8].

The experience with this project indicates that trust issues are important for well-functioning networks. Since all companies developed new products or services, intellectual property rights (IPR) and patents were important. In the SIMPLE-model, we tried to achieve a balance between openness to present and share new ideas and the protection of these ideas (secrecy). Such issues were thoroughly discussed at the first network meeting and a contract governing secrecy was presented. However, no group signed any contract but instead a verbal agreement was reached. In short, that agreement regulated openness between participants and active participation with the awareness to not mention issues that might hinder such things as patent applications. A general agreement also was concluded not to mention details to people outside the network. These "gentlemen's agreements" proved to be sufficient and we have not experienced any problems with IPR. The oral agreement was sufficient and an open atmosphere contributed to sharing of experiences and mutual learning in the networks.

One important learning outcome from conducting the project is that company perspectives must come first. This can be discouraging for the researcher or business developer who has developed a tool or an approach that the companies are supposed to follow. We tried to minimize the formal procedures and document writing by focusing on the development project as such. The coaching was mainly in the form of discussions with the business leaders so as to help them find the right competencies for their needs. Here the extra funding via the consultancy checks was very useful for companies seeking help from consultants, researchers, etc.

Most likely, the method described in this article can be applied in any type of project trying to stimulate small businesses development of products and services. Important building stones are strong networks, access to a broad group of resource organizations, and some extra money to stimulate the companies to seek help from outside their own organizations.

\section{Acknowledgements}

This project was financed by European Regional Development Fund. 


\section{References}

[1] A. Gibb and M. Scott. Understanding small firms growth, in: Small firms growth and development, M. Scott, A. Gibb, J. Lewis and T. Faulkner. Blackmore Press. Dorset. 1986.

[2] K.T. Ulrich and S. D. Eppinger. Product design and development, Second edition. Irwin McGraw-Hill, Boston. 2000.

[3] O. Hjelm. "Advantage Eco-design": A partnership for promoting eco-design activities in small companies. Proceedings: Partnership for Sustainable Development. November 7-10, 2004. 12th International Conference of Greening of Industry Network, Hong Kong.

[4] A.E.W. Rennie. C.G. Lambert. N.J. Baker and O. Hjelm. A transnational approach to the implementation of eco-design methodologies in SMEs. Presented at the 5th International Conference on Design and Manufacture for Sustainable Development, Loughboroug, UK 10-11 July 2007.

[5] G, Zilahy, D. Huisingh, M. Melanen, V.D. Phillip, and J. Sheffy, Roles of academia in regional sustainability initiatives: outreach for a more sustainable future. Journal of Cleaner Production 17, 2009, pp 1053-1056

[6] J.C. Stephens, M.E. Hernandez, M . Román, A.C. Graham, and R.W. Scholz. Higher education as a change agent for sustainability in different cultures and contexts. International Journal of Sustainability in Higher Education 9, 2008, pp 317-338.

[7] Nutek 2004:10. Tio frågor och svar om samverkan i småföretag. In Swedish.

[8] K. Elmhester. Små företag i strategiska nätverk - hur påverkas det enskilda företagets utveckling? Linköping Studies in Science and Technology Dissertations, No.1217. 2008. In Swedish 